\title{
Main and Epistatic Quantitative Trait Loci Associated with Seed Size in Watermelon
}

\author{
Jason Prothro, Katherine Sandlin, and Hussein Abdel-Haleem \\ Institute of Plant Breeding, Genetics and Genomics, 111 Riverbend Road, University of Georgia, \\ Athens, GA 30602 \\ Eleni Bachlava, Victoria White, and Steven Knapp \\ Monsanto, Woodland, CA 95695 \\ Cecilia McGregor ${ }^{1}$ \\ Department of Horticulture and Institute of Plant Breeding, Genetics and Genomics, University of \\ Georgia, 1111 Miller Plant Sciences, Athens, GA 30602
}

\begin{abstract}
AdDitional InDEX words. seed weight, length, width, M-QTL, E-QTL
Abstract. Watermelon (Citrullus lanatus) is an important crop grown for both its edible flesh and seeds. Seed size is an important trait in watermelon breeding, with large seeds preferred for planting and edible seeds but small seeds preferred in fruit sold for consumption. Large, medium, and small seed sizes are thought to be controlled by two genes with epistatic interaction. A 'Klondike Black Seeded' $\times$ 'New Hampshire Midget' $($ KBS $\times$ NHM) recombinant inbred line population and a ZWRM $50 \times$ PI $244019\left(Z W R M \times\right.$ Citroides) $F_{2}$ population were used to identify main effect quantitative trait loci (M-QTL) and epistatic QTL (E-QTL) associated with 100 seed weight (100SWT), seed length (SL), and seed width (SWD). Thirteen M-QTL were identified on four linkage groups (LGs) for the three traits in the two populations. Major M-QTL $\left(R^{2}=\mathbf{2 6 . 9 \%}\right.$ to $\left.\mathbf{7 3 . 6} \%\right)$ were identified at the same location on LG 2 in both populations for all three traits. M-QTL for all three traits also colocalized on LG 9 in the ZWRM $\times$ Citroides population and on LG 4 for 100 SWT and SL in the KBS $\times$ NHM population. Significant epistatic effects were found between the M-QTL on LG 2 and LG 4 in the KBS $\times$ NHM population and between LG 2 and LG 9 in the ZWRM $\times$ Citroides population. The phenotypic variance explained by the E-QTL was generally small. The stable, major M-QTL on LG 2 is a candidate for marker-assisted selection for seed size in watermelon.
\end{abstract}

Watermelon $(2 \mathrm{n}=2 \mathrm{x}=22)$ is the most economically important species in the genus Citrullus, in a family that also includes melon (Cucumis melo), cucumber (Cucumis sativus var. sativus), summer squash (Cucurbita pepo), and pumpkin (Cucurbita sp.) (Robinson and Decker-Walters, 1997). Watermelon production is mainly focused on the edible flesh of the fruit, placing a premium on fruit characteristics. Seed size is important because watermelon breeders aim to develop hybrid cultivars with large seed for planting (especially where direct seeding is used), but that will produce fruit with small seed (J. Bernier, personal communication). In the United States, where seedless fruit are popular (U.S. Department of Agriculture, 2011), this strategy is still followed to minimize the size of the white seedcoat in the seedless fruit.

In some parts of the world such as Nigeria and China, C. lanatus is grown not for its edible flesh, but its edible seeds (Gusmini et al., 2004; Jensen et al., 2011; Munisse et al., 2011; Zhang, 1996a). In some cases the edible seeds are of a unique seed type (e.g., "egusi"), but in China, the edible seeds are similar to those found in watermelon grown for edible flesh. Seed size is an important trait for selection in these cultivars with a seed width of $\approx 11 \mathrm{~mm}$ desired for profitability (Zhang, 1996a).

Watermelon seed size has traditionally been divided into qualitative categories as being large, medium, small, tomato, or tiny (Hawkins et al., 2001; Poole et al., 1941; Zhang, 1996b).

Received for publication 7 Aug. 2012. Accepted for publication 13 Sept. 2012. This research was funded by Monsanto. Patent protection has been sought for the QTL described herein.

${ }^{1}$ Corresponding author. E-mail: cmcgre1@uga.edu.
Poole et al. (1941) defined large, medium, and small seed as having average seed lengths of 13,10 , and $6 \mathrm{~mm}$, respectively. Tomato seed are approximately the same size as tomato seed, whereas tiny seed size is smaller than $5 \mathrm{~mm}$ but larger than tomato seed size (Gusmini, 2005; Wehner et al., 2001). High correlations $(r=\approx 0.9)$ among seed weight, seed length, and seed width have been reported (Hawkins et al., 2001; Poole et al., 1941; Zhang et al., 1995), suggesting a pleiotropic effect and leading to seed size usually being described in terms of seed length .

Poole et al. (1941) suggested that two genes, $l$ and $s$, control seed length for large, medium, and small seed sizes with mediumsized seed being dominant and $s$ epistatic to $l$. The suggested genotypes for long, medium, and short seeds are $l l S-, L-S$-, and $-s S$, respectively (Poole et al., 1941). Several subsequent studies involving crosses between medium and long seed confirmed the dominance of medium seed over long seed and seed size controlled by a single dominant gene (Konsler and Barham, 1958; Lou, 2009; Shimotsuma, 1963), which still fits Poole's model. However, Lou (2009) also found that results from some crosses did not fit single dominant gene inheritance, and Tanaka et al. (1995) reported that the tiny seed size in the cultivar Sweet Princess was controlled by a single gene (Ti), whereas Zhang (1996b) reported that the tomato seed size is controlled by a single recessive gene ( $t s)$.

Advances in molecular genetics have made it possible to select plants based on genetic markers linked to traits of interest, a process called marker-assisted selection [MAS (Michelmore, 1995; Ribaut and Hoisington, 1998; Young, 1996)]. The availability of high-quality genetic maps is crucial to the identification of QTL associated with specific traits. Until recently the genetic marker resources available 


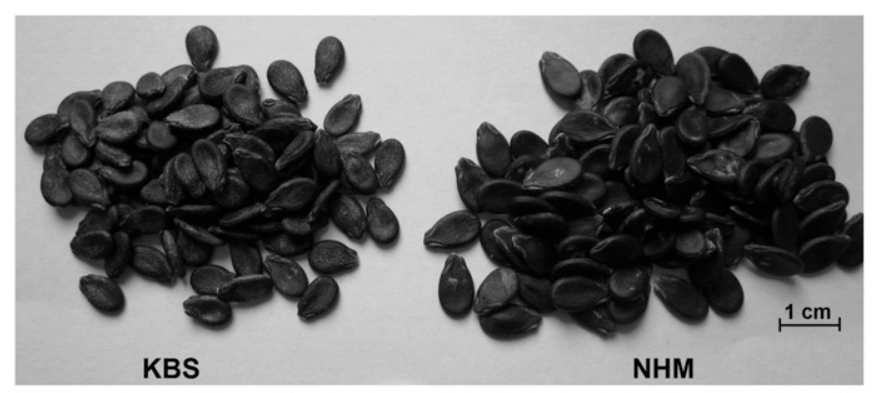

A

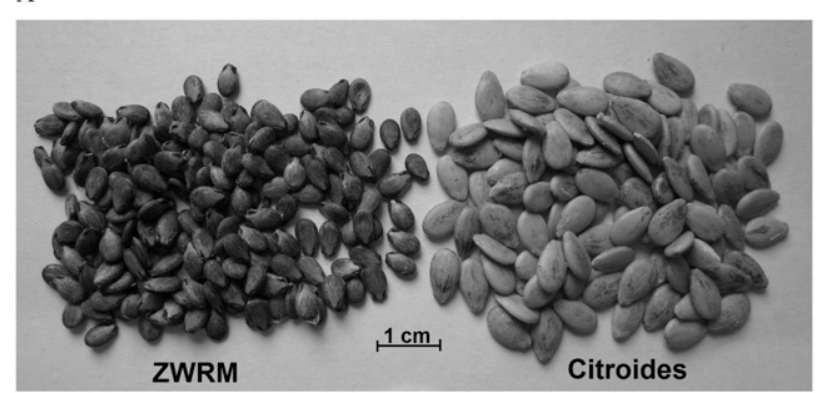

B

Fig. 1. Seed phenotypes of the parents of the two watermelon mapping populations: (A) 'Klondike Black Seeded' [KBS (medium)] and 'New Hampshire Midget' [NHM (medium)] and (B) ZWRM 50 [ZWRM (small)] and PI 244019 [Citroides (medium)].

Table 1. Pearson correlations for 100 seed weight (100SWT), seed length (SL), and seed width (SWD) in the 'Klondike Black Seeded' $\times$ 'New Hampshire Midget' $(\mathrm{KBS} \times \mathrm{NHM})$ and ZWRM $50 \times$ PI 244019 (ZWRM $\times$ Citroides) watermelon populations.

\begin{tabular}{lcc}
\hline KBS $\times$ NHM & $100 S W T$ & SL \\
\hline SL & $0.88^{*^{\mathrm{z}}}$ & \\
SWD & $0.86^{*}$ & $0.93^{*}$ \\
ZWRM $\times$ Citroides & 100 SWT & SL \\
\hline SL & $0.95^{*}$ & \\
SWD & $0.96^{*}$ & $0.97^{*}$
\end{tabular}

${ }^{\mathrm{z}}$ Asterisks indicate significant correlations at $P<0.001$.

for watermelon were limited as a result of the lack of highly polymorphic marker technologies and the narrow genetic base of commercial cultivars (Levi et al., 2001a, 2001b, 2004). The only previous effort to find genetic markers for seed size used single factor analysis and identified a single random amplified polymorphic DNA (RAPD) marker loosely associated with watermelon seed length and seed width (Hawkins et al., 2001). Recently, single nucleotide polymorphism (SNP) genetic maps were produced using diverse C. lanatus parents, including a population produced from an elite $\times$ elite $(C$. lanatus var. lanatus) cross and a population from an intersubspecific cross between C. lanatus var. lanatus and C. lanatus var. citroides (Sandlin et al., 2012). Because these genetically diverse mapping populations segregate for seed size, it is our aim to use them to identify M-QTL and E-QTL (Klimenko et al., 2010; Ravi et al., 2011) associated with seed size in watermelon.

\section{Materials and Methods}

Plant Materials and genetic MaP. The development of the mapping populations and creation of the genetic maps have
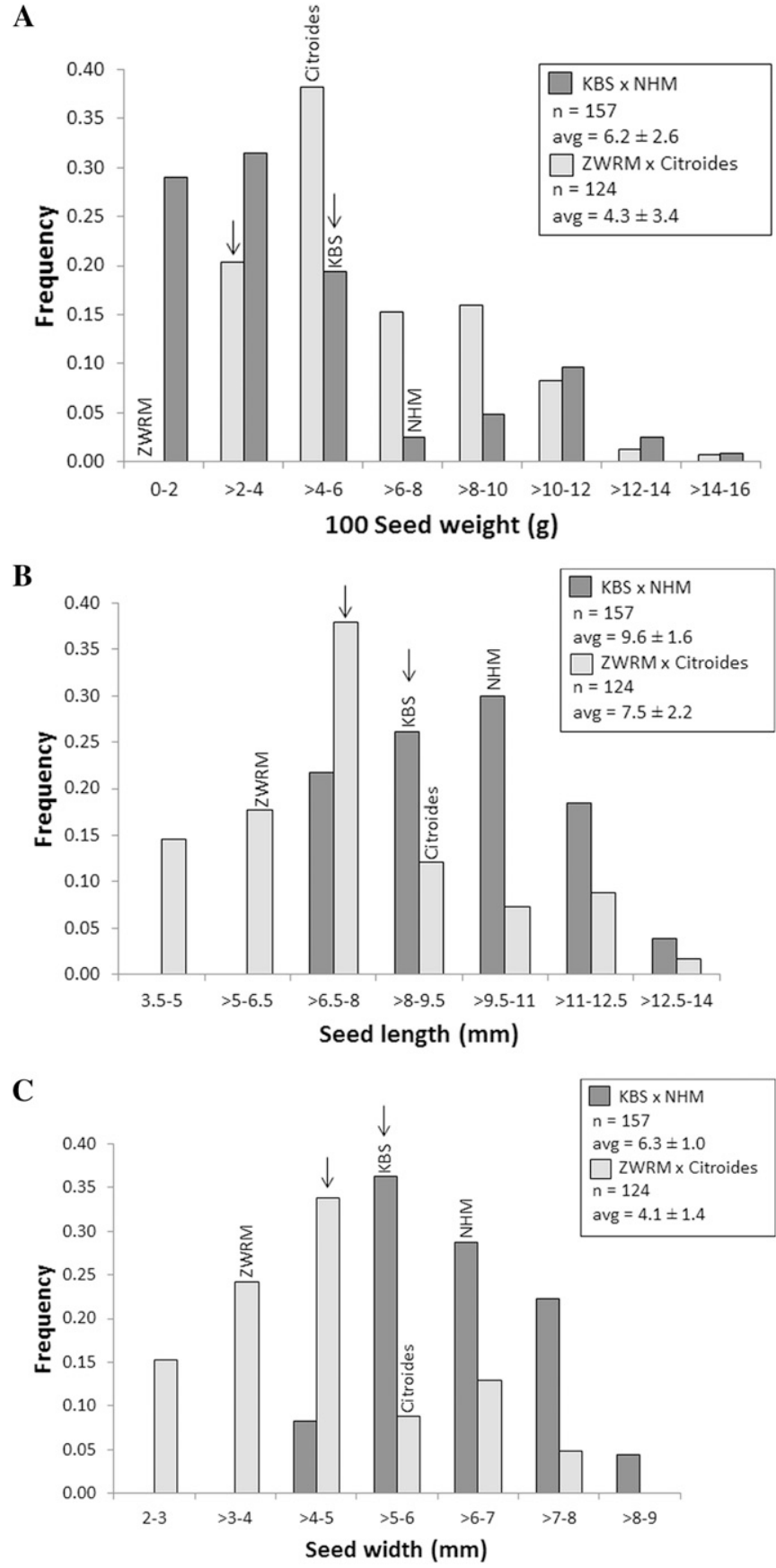

Fig. 2. Frequency distribution for watermelon (A) 100 seed weight, (B) seed length, and $(\mathbf{C})$ seed width in the 'Klondike Black Seeded' $\times$ 'New Hampshire Midget' $\left(\right.$ KBS $\times$ NHM) and ZWRM $50 \times$ PI $244019($ ZWRM $\times$ Citroides $) F_{2}$ populations. The parental (KBS, NHM, ZWRM, and Citroides) and $F_{1}$ (arrows) phenotypes are also indicated.

been described previously (Sandlin et al., 2012). Briefly, a recombinant inbred line population [RIL $\left(\mathrm{F}_{6}\right)$ ] was developed by single seed descent from a cross between the elite cultivars Klondike Black Seeded (PI 635609) and New Hampshire Midget (PI 635617) and an $\mathrm{F}_{2}$ population was created from a cross between C. lanatus var. lanatus ZWRM 50 from China (PI 593359) and a wild C. lanatus var. citroides accession from South Africa (PI 244019). SNP markers were developed for $C$. lanatus and used to create genetic maps with 378 markers for 
the KBS $\times$ NHM population and 338 markers for the ZWRM $\times$ Citroides population (Sandlin et al., 2012).

The weight of 100 seeds (100SWT) for KBS, NHM, ZWRM, and Citroides were 4.96, 6.68, 2.00, and $5.44 \mathrm{~g}$, respectively. The average SL of 10 randomly chosen seed of each parent were $8.38,10.67,6.16$, and $8.59 \mathrm{~mm}$, whereas the SWDs were 5.30, 6.55, 3.69, and $5.01 \mathrm{~mm}$ (Fig. 1).

Trait Phenotyping. A single plant for each $\mathrm{KBS} \times \mathrm{NHM} \mathrm{F}_{6}$ RIL line and individual ZWRM $\times$ Citroides $\mathrm{F}_{2}$ plants were grown in the greenhouse at the University of Georgia's campus in Athens in 2009 to 2010 and 2007, respectively. For both populations, seed were germinated in seedling trays and transplanted 4 weeks later into 14.136-L blow-molded pots (C1600; Nursery Supplies, Kissimmee, FL) filled with Fafard 3B mix (Conrad Fafard, Agawam, MA) and $12 \mathrm{~g}$ Osmocote (14N4.2P-11.6K; Scotts Miracle-Gro, Marysville, $\mathrm{OH}$ ) per pot. The average greenhouse temperature varied from 21.1 to $26.6^{\circ} \mathrm{C}$ in Spring 2010 and from 25.5 to $35.5^{\circ} \mathrm{C}$ in Summer 2007. One mature fruit was collected from each plant in April and May 2010 for the KBS $\times$ NHM population and July and Aug. 2007 for the ZWRM $\times$ Citroides population.

The seed were harvested by hand and allowed to dry at $40 \%$ to $50 \%$ relative humidity and $24{ }^{\circ} \mathrm{C}$ for $48 \mathrm{~h}$ before measurements were taken for 100SWT in grams and SL and SWD in millimeters measured with a digital caliper (Balkamp Manufacturing Corp., Indianapolis, IN). The SL and SWD values used for QTL mapping were the average measurements of five random seeds per fruit.

Quantitative Trait loci Detection. Analysis for the detection of M-QTL was performed using WinQTL Cartographer (WinQTL Cart) Version 2.5 (Wang et al., 2011). All data were analyzed by composite interval mapping (CIM) (Zeng, 1993, 1994) and the threshold values for each trait (Churchill and Doerge, 1994; Doerge and Churchill, 1996) were determined using permutation tests (1000 permutations, $\alpha=0.05)$. The standard model (Model 6) with a walk speed of $1 \mathrm{cM}$ was used for CIM analysis. QTL identified on the same LG were considered separate QTL if they were separated by at least $20 \mathrm{cM}$
(Ravi et al., 2011). QTL were considered minor, intermediate, and major if $R^{2}$ was less than $10 \%$, between $10 \%$ and $25 \%$, and greater than $25 \%$, respectively.

Analysis for epistatic interaction between M-QTL was carried out using multiple interval mapping (MIM) (Kao and Zeng, 1997; Kao et al., 1999; Zeng et al., 1999) in WinQTL Cart Version 2.5. The information criteria $\mathrm{IC}(\mathrm{k})=-2[\log (\mathrm{L})-$ $\mathrm{kc}(\mathrm{n}) / 2$ ] and penalty function $\mathrm{c}(\mathrm{n})=\log (\mathrm{n})$ were used to determine significance.

\section{Results and Discussion}

Correlations between the three seeds traits were statistically significant and high in both populations but somewhat higher in the ZWRM $\times$ Citroides population than in the $\mathrm{KBS} \times \mathrm{NHM}$ population (Table 1). Transgressive segregation was observed for all three traits (Fig. 2) suggesting the involvement of antagonistic additive effects (deVicente and Tanksley, 1993; Rieseberg et al., 1999).

A total of 13 QTL were identified in the two populations for the three traits (Table 2; Fig. 3). In the KBS $\times$ NHM population, three, two, and one QTL were detected for 100SWT, SL, and SWD, respectively, whereas two (100SWT), three (SL), and two $(\mathrm{SWD})$ were identified in the ZWRM $\times$ Citroides population. In both populations, major M-QTL were detected for 100SWT $\left(R^{2}=26.9 \%\right.$ and $\left.73.6 \%\right)$, SL $\left(R^{2}=41.3 \%\right.$ and $\left.69.2 \%\right)$, and SWD $\left(R^{2}=32.8 \%\right.$ and $\left.69.3 .2 \%\right)$ at a similar location on LG 2 (Table 2; Fig. 3). Colocalization of QTL for different traits at similar chromosomal locations may indicate a single gene with pleiotropic effect or different tightly linked genes. Fine mapping of the region is needed to elucidate this effect, but the consistent high correlation between the traits in this and other studies suggest pleiotropism (Poole et al., 1941; Zhang et al., 1995).

QTL that are stable across different genetic backgrounds are highly desirable for MAS. The observation that QTL identified in a particular mapping population are not useful in populations with different genetic backgrounds has been a major limiting

Table 2. Genomic regions associated with main quantitative trait loci for 100 seed weight (100SWT), seed length (SL), and seed width (SWD) in the 'Klondike Black Seeded' $\times$ 'New Hampshire Midget' $($ KBS $\times$ NHM) and ZWRM $50 \times$ PI $244019($ ZWRM $\times$ Citroides $)$ watermelon populations.

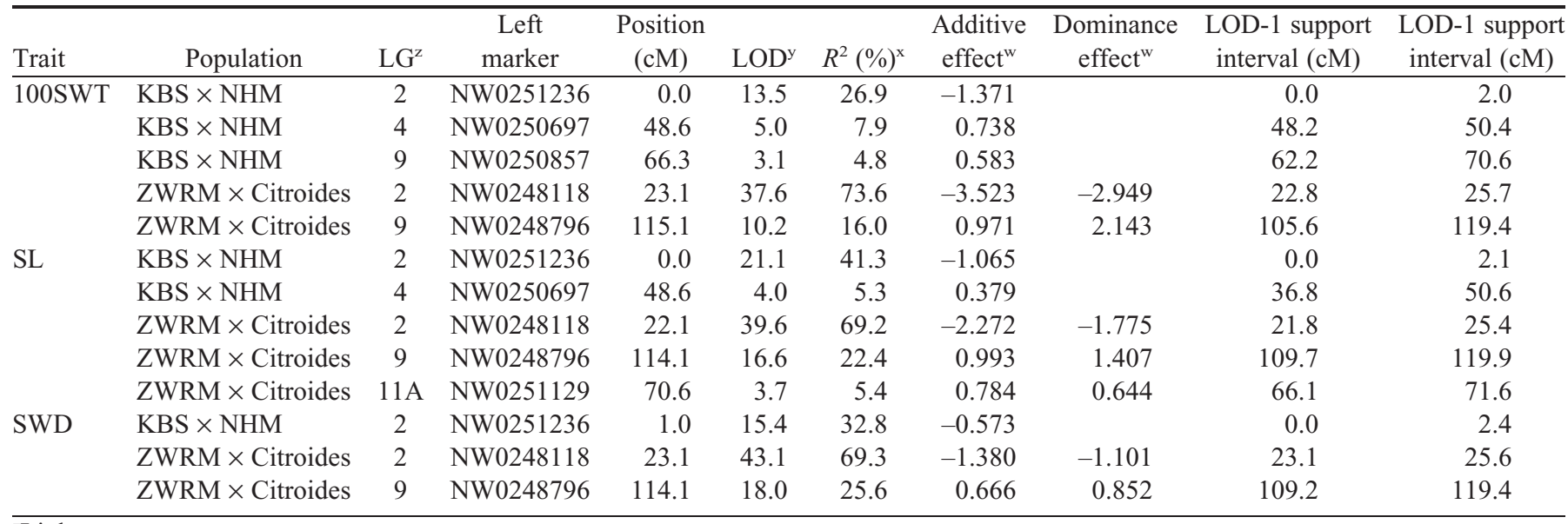

${ }^{\mathrm{z}}$ Linkage group.

${ }^{\mathrm{y}} \log _{10}$ likelihood ratio.

xPhenotypic variation explained.

wegative values indicate that the effect is contributed by the allele from male parent. 


\section{LG2_ZWRMxCitroides}

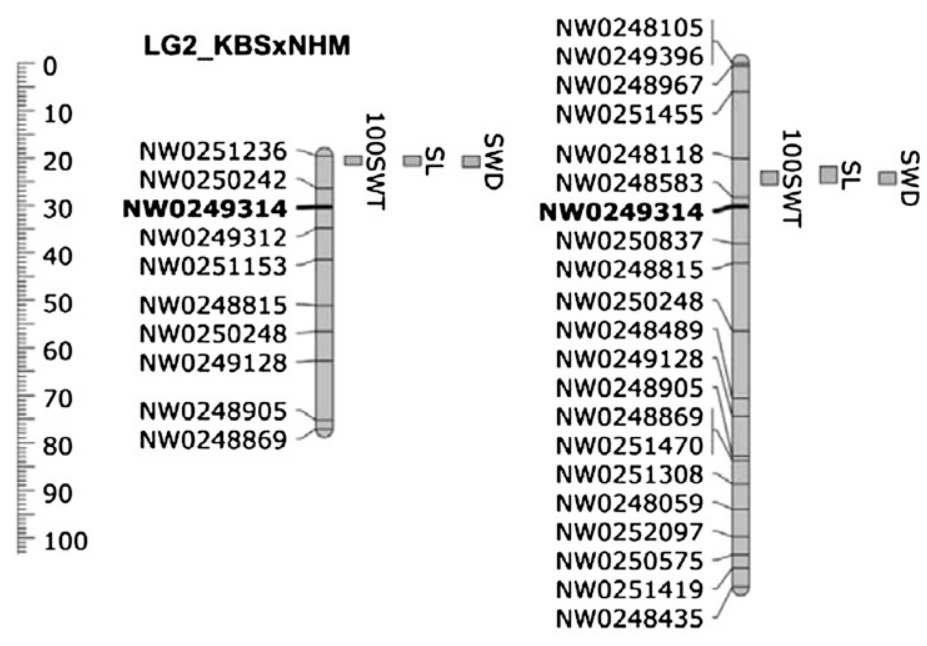

\section{LG9_ZWRMxCitroides}

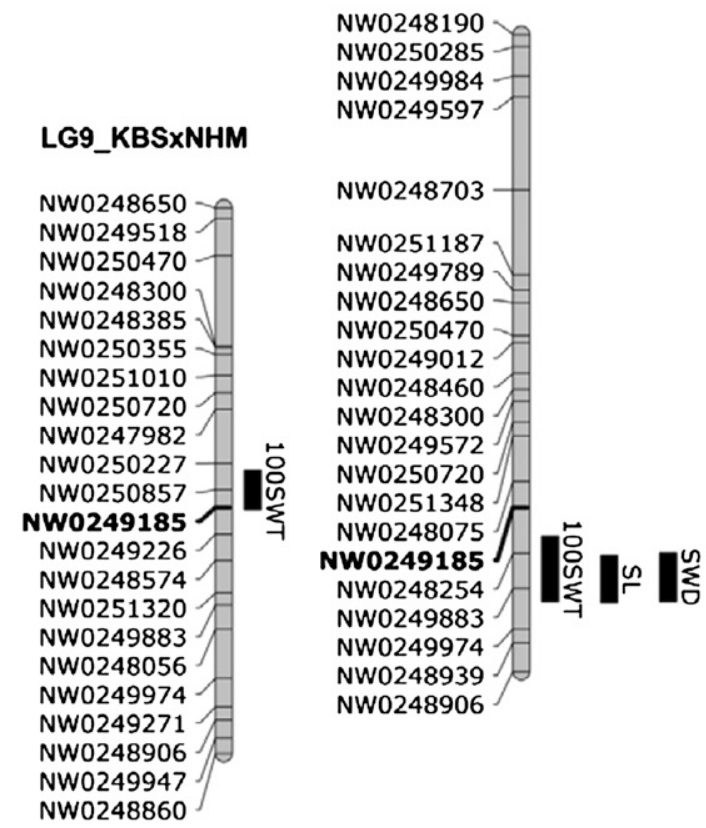

\section{LG4_KBSXNHM}

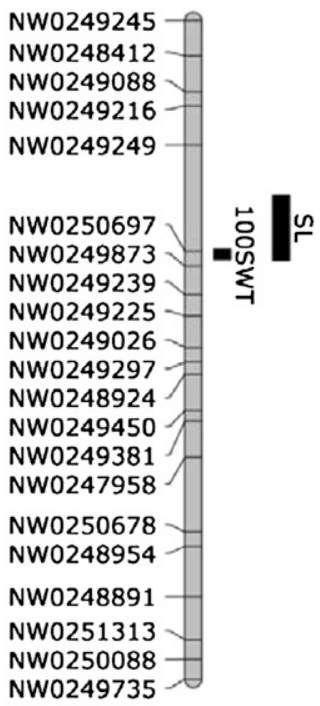

LG11A_ZWRMXCitroides

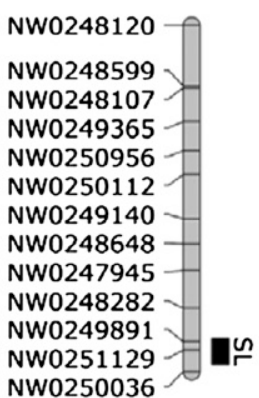

Fig. 3. Quantitative trait loci (QTL) identified for watermelon 100 seed weight (100SWT), seed length (SL), and seed width (SWD) in the 'Klondike Black Seeded' $\times$ 'New Hampshire Midget' (KBS $\times$ NHM) and ZWRM $50 \times$ PI 244019 (ZWRM $\times$ Citroides) populations are indicated as bars. The length of the bar is equal to the 1LOD support interval. Solid and shaded bars represent loci where the maternal parent and paternal parent contribute the additive effect, respectively. A shared marker between the two populations close to the QTL is shown in bold to facilitate positional comparisons between populations. The cM scale on the right and the figure was produced using MapChart version 2.1 (Voorrips, 2002).

factor in the widespread application of MAS in breeding programs (Collard and Mackill, 2008). The large amount of phenotypic variation explained $(26.9 \%$ to $73.6 \%)$ by the M-QTL on LG 2 and its stability across populations makes it the prime target for MAS for seed size.

In addition to the stable M-QTL on LG 2, an additional M-QTL for 100SWT and SL were identified on LG 4 in the KBS $\times$ NHM population. This minor M-QTL had an antagonistic additive effect for these traits to the major M-QTL on LG 2, in agreement with expectations based on the observed transgressive trait segregation (Fig. 2). An M-QTL for 100SWT identified on LG 9 in the KBS $\times$ NHM population was located at a slightly different location on the same LG than the intermediate-high M-QTL for 100SWT, SL, and SWD in the ZWRM $\times$ Citroides population. Hawkins et al. (2001) identified a RAPD marker loosely linked to SL and SWD in an intersubspecific $C$. lanatus population similar to the $\mathrm{ZWRM} \times$ Citroides population. Because no markers are shared between the studies, it is not possible to determine whether the RAPD marker might be linked to any of the M-QTL detected in the current study.

It has been reported that there is an epistatic interaction between the genes controlling seed size in watermelon (Poole 
et al., 1941). MIM was used in an effort to detect such interactions in the current study. Significant epistatic interactions were detected between the M-QTL on LG 2 and LG 4 for 100SWT and SL in the KBS $\times$ NHM population and LG 2 and LG 9 for all three traits in the ZWRM $\times$ Citroides population (Table 3). The effect of the epistatic interactions was relatively small with only the interaction between LG 2 and LG 4 for 100SWT above 5\% $\left(R^{2}=7.4 \%\right)$.

The M-QTL on LG 4 was not detected in the ZWRM $\times$ Citroides population. It should however be kept in mind that this is an intersubspecific cross between Clanatus var. lanatus and $C$. lanatus var. citroides, whereas the study by Poole et al. (1941) and others (Lou, 2009; Tanaka et al., 1995; Zhang, 1996b) involved intrasubspecific crosses (similar to KBS $\times$ NHM). The population used by Hawkins et al. (2001) was similar to the ZWRM $\times$ Citroides population and assigned genes controlling SL and SWD to a single LG. However, in the current study the genetic background and environmental effects are confounded, which means that it is not possible to determine whether the differences between populations are the result of the different genetic backgrounds or the different environments. Therefore, QTL detected in only one population/ environment should be considered with caution until more data become available.

The M-QTL identified on LG 9 is at a similar location to fruit size QTL detected in these populations (Sandlin et al., 2012). A significant correlation $(r=0.20$ to 0.27$)$ between SL and SWD and fruit length and width was observed in the ZWRM $50 \times$ Citroides population (data not shown) (Prothro, 2010). It is possible that seed size in the current study was influenced by conditions in the greenhouse that can limit fruit size, and it remains to be seen whether the QTL on LG 9 are associated with seed size under field conditions.

It is difficult to determine with certainty whether any of the identified M-QTL represent the $s$ or $l$ genes described by Poole et al. (1941). It is tempting to speculate that the QTL on LG 2 and LG 4 are associated with these genes, but the absence of small seeds $(\approx 6 \mathrm{~mm})$ in the KBS $\times$ NHM RIL population (Fig. 2B) suggests that the population was not segregating for the $s$ alleles. It is clear that more than one gene is involved in determining seed size and that there is an interaction between the genes. A caveat of the present study is that both populations were grown in the greenhouse; however, the stability of the

Table 3. Significant epistatic interactions between main quantitative trait loci for 100 seed weight (100SWT), seed length (SL). and seed width $(\mathrm{SWD})$ in the 'Klondike Black Seeded' $\times$ 'New Hampshire Midget' $($ KBS $\times$ NHM) and ZWRM $50 \times$ PI $244019($ ZWRM $\times$ Citroides) watermelon populations.

\begin{tabular}{lccccc}
\hline Trait & Population & $\begin{array}{c}\text { Linkage } \\
\text { groups }\end{array}$ & $\begin{array}{c}\text { Type of } \\
\text { interaction }^{z}\end{array}$ & $\begin{array}{c}\text { Phenotypic } \\
\text { effect }\end{array}$ & $\begin{array}{c}\text { Effect } \\
(\%)\end{array}$ \\
\hline 100SWT & KBS $\times$ NHM & $2 \times 4$ & $\mathrm{~A} \times \mathrm{A}$ & -0.66 & $7.40 \%$ \\
& ZWRM $\times$ & $2 \times 9$ & $\mathrm{~A} \times \mathrm{A}$ & -1.31 & $1.20 \%$ \\
& Citroides & & & & \\
SL & KBS $\times$ NHM & $2 \times 4$ & $\mathrm{~A} \times \mathrm{A}$ & -0.30 & $2.80 \%$ \\
& ZWRM $\times$ & $2 \times 9$ & $\mathrm{~A} \times \mathrm{A}$ & -0.36 & $1.43 \%$ \\
& Citroides & & & & \\
SWD & KBS $\times$ NHM & None & & & \\
& ZWRM $\times$ & $2 \times 9$ & $\mathrm{D} \times \mathrm{A}$ & -0.22 & $0.27 \%$ \\
& Citroides & & & & \\
\hline
\end{tabular}

${ }^{\mathrm{z}} \mathrm{A} \times \mathrm{A}=$ additive $\times$ additive; $\mathrm{D} \times \mathrm{A}=$ dominant $\times$ additive.
M-QTL on LG 2 across years and diverse genetic backgrounds suggests broad stability.

We have identified main and epistatic QTL that control seed size in watermelon. The M-QTL on LG 2 is a potential target for MAS of seed size in watermelon breeding programs.

\section{Literature Cited}

Churchill, G.A. and R.W. Doerge. 1994. Empirical threshold values for quantitative trait mapping. Genetics 138:963-971.

Collard, B.C.Y. and D.J. Mackill. 2008. Marker-assisted selection: An approach for precision plant breeding in the twenty-first century. Philosophical Trans. Royal Soc. B 363:557-572.

deVicente, M.C. and S.D. Tanksley. 1993. QTL analysis of transgressive segregation in an interspecific tomato cross. Genetics 134: $585-596$.

Doerge, R.W. and G.A. Churchill. 1996. Permutation tests for multiple loci affecting a quantitative character. Genet. Mol. Biol. 142:285294

Gusmini, G. 2005. Inheritance of fruit characteristics and disease resistance in watermelon [Citrullus lanatus (Thunb.) Matsum. \& Nakai]. PhD diss., North Carolina State Univ., Raleigh, NC.

Gusmini, G., T.C. Wehner, and R.L. Jarret. 2004. Inheritance of egusi seed type in watermelon. J. Hered. 95:268-270.

Hawkins, L.K., F. Dane, and T.L. Kubisiak. 2001. Molecular markers associated with morphological traits in watermelon. HortScience 36:1318-1322.

Jensen, B.D., F.M. Touré, M. Ag Hamattal, F.A. Touré, and A.D. Nantoumé. 2011. Watermelons in the sand of Sahara: Cultivation and use of indigenous landraces in the Tombouctou region of Mali. Ethnobot. Res. Appl. 9:151-162.

Kao, C.-H. and Z.-B. Zeng. 1997. General formulas for obtaining the MLEs and the asymptotic variance-covariance matrix in mapping quantitative trait loci when using the EM algorithm. Biometrics 53:653-665.

Kao, C.-H., Z.-B. Zeng, and R.D. Teasdale. 1999. Multiple interval mapping for quantitative trait loci. Genetics 152:1203-1216.

Klimenko, I., N. Razgulayeva, M. Gau, K. Okumura, A. Nakaya, S. Tabata, N. Kozlov, and S. Isobe. 2010. Mapping candidate QTLs related to plant persistency in red clover. Theor. Appl. Genet. 120:1253-1263.

Konsler, T.R. and W.S. Barham. 1958. The inheritance of seed size in watermelon. Proc. Amer. Soc. Hort. Sci. 71:480-484.

Levi, A., C.E. Thomas, A.P. Keinath, and T.C. Wehner. 2001a. Genetic diversity among watermelon (Citrullus lanatus and Citrullus colocynthis) accessions. Genet. Resources Crop Evol. 48:559566.

Levi, A., C.E. Thomas, M. Newman, O.U.K. Reddy, X. Zhang, and Y. Xu. 2004. ISSR and AFLP markers differ among American watermelon cultivars with limited genetic diversity. J. Amer. Soc. Hort. Sci. 129:553-558.

Levi, A., C.E. Thomas, T.C. Wehner, and X. Zhang. 2001b. Low genetic diversity indicates the need to broaden the genetic base of cultivated watermelon. HortScience 36:1096-1101.

Lou, L. 2009. Inheritance of fruit characteristics in watermelon [Citrullus lanatus (Thunb.) Matsum. \& Nakai]. MS thesis, North Carolina State Univ., Raleigh, NC.

Michelmore, R. 1995. Molecular approaches to manipulation of disease resistance genes. Annu. Rev. Phytopathol. 33:393-427.

Munisse, P., S.B. Andersen, B.D. Jensen, and J.L. Christiansen. 2011. Diversity of landraces, agricultural practises and traditional uses of watermelon (Citrullus lanatus) in Mozambique. African J. Plant Sci. 5:75-86.

Poole, C.F., P.C. Grimball, and D.R. Porter. 1941. Inheritance of seed characters in watermelon. J. Agr. Res. 63:433-456.

Prothro, J.M. 2010. Genetic mapping of phenotypic and quantitative trait loci underlying horticulturally important traits in watermelon. MS thesis, Univ. of Georgia, Athens, GA. 
Ravi, K., V. Vadez, S. Isobe, R. Mir, Y. Guo, S. Nigam, M. Gowda, T. Radhakrishnan, D. Bertioli, S. Knapp, and R. Varshney. 2011. Identification of several small main-effect QTLs and a large number of epistatic QTLs for drought tolerance related traits in groundnut (Arachis hypogaea L.). Theor. Appl. Genet. 122:1119-1132.

Ribaut, J.-M. and D. Hoisington. 1998. Marker-assisted selection: New tools and strategies. Trends Plant Sci. 3:236-239.

Rieseberg, L.H., M.A. Archer, and R.K. Wayne. 1999. Transgressive segregation, adaptation and speciation. Heredity 83:363-372.

Robinson, R.W. and D.S. Decker-Walters. 1997. Cucurbits. CAB International, Wallingford, UK.

Sandlin, K.C., J.M. Prothro, A.F. Heesacker, N. Khalilian, R. Okashah, W. Xiang, E. Bachlava, D. Caldwell, D. Seymour, V. White, E. Chan, G. Tolla, C. White, D. Safran, E. Graham, S.J. Knapp, and C.E. McGregor. 2012. Comparative mapping in watermelon [Citrullus lanatus (Thunb.) Matsum. et Nakai]. Theor. Appl. Genet. doi: 10.1007/s00122-012-1938-z.

Shimotsuma, M. 1963. Cytogenetical studies in the genus Citrullus. VII. Inheritance of several characters in watermelons. Jpn. J. Breeding 13:235-240.

Tanaka, T., S. Wimol, and T. Mizutani. 1995. Inheritance of fruit shape and seed size of watermelon. J. Jpn. Soc. Hort. Sci. 64:543-548.

U.S. Department of Agriculture. 2011. 2010 agricultural statistics. 9 July 2011. <http://www.nass.usda.gov/Publications/Ag_Statistics/ 2010/index.asp $>$.
Voorrips, R.E. 2002. MapChart: Software for the graphical presentation of linkage maps and QTLs. J. Hered. 93:77-78.

Wang, S., C.J. Basten, and Z.B. Zeng. 2011. Windows QTL Cartographer 2.5. Dept. of Statistics, North Carolina State Univ., Raleigh, NC.

Wehner, T.C., N.V. Shetty, and G.W. Elmstron. 2001. Breeding and seed production, p. 27-73. In: Maynard, D.N. (ed.). Watermelons: Characteristics, production, and marketing. ASHS Press, Alexandria, VA.

Young, N.D. 1996. QTL mapping and quantitative disease resistance in plants. Annu. Rev. Phytopathol. 34:479-501.

Zeng, Z.B. 1993. Theoretical basis of separation of multiple linked gene effects on mapping quantitative trait loci. Proc. Natl. Acad. Sci. USA 90:10972-10976.

Zeng, Z.B. 1994. Precision mapping of quantitative trait loci. Genetics 136:1457-1468.

Zeng, Z.B., C.H. Kao, and C.J. Basten. 1999. Estimating the genetic architecture of quantitative traits. Genet. Res. 74:279-289.

Zhang, J. 1996a. Breeding and production of watermelon for edible seed in China. Cucurbit Genet. Coop. Rpt. 19:66-67.

Zhang, J.N. 1996b. Inheritance of seed size from diverse crosses in watermelon. Cucurbit Genet. Coop. Rpt. 19:67-69.

Zhang, X.P., B.B. Rhodes, and M. Wang. 1995. Genes controlling watermelon seed size, p. 144-147. In: Lester, G. and J. Dunlap (eds.). Cucurbitaceae '94: Evaluation and enhancement of cucurbit germplasm. ASHS Press, Alexandria, VA. 